\title{
Mobilidade Urbana Sustentável para Cidades Inteligentes
}

\author{
Sustainable Urban Mobility for Smart Cities
}

Recebido: 07/01/2022 | Revisado: 09/01/2022 |Aceito: 16/01/2022 | Publicado: 17/01/2022

\author{
Lucas Vitor Andrade Lima \\ ORCID: https://orcid.org/0000-0001-8939-1367 \\ Universidade Federal de Campina Grande, Brasil \\ E-mail: lucasvitorc1@gmail.com \\ Isabel Lausanne Fontgalland \\ ORCID: https://orcid.org/0000-0002-0087-2840 \\ Universidade Federal de Campina Grande, Brasil \\ E-mail: isabelfontgalland@gmail.com
}

\begin{abstract}
Resumo
Os modais de transportes de alta qualidade são eficazes, agregando dinamismo na economia em cidades inteligentes e sustentáveis, contribuindo para transformações na estrutura econômica produtiva. Portanto, existe consenso sobre a impossibilidade de que uma sociedade consiga atingir grandes níveis de desenvolvimento econômico sem adoção de um sistema de transporte eficiente, uma vez que a evolução da economia traz consigo a necessidade de que a infraestrutura seja ampliada, especialmente a que se refere à mobilidade urbana. Se o Código de Trânsito Brasileiro (Lei Nacional 9.503/1997) contém disposições normativas importantes e que devem ser levadas em consideração na elaboração da política de mobilidade urbana, fica evidente que este é um ponto de desenvolvimento socioeconômico sustentável. Em 3 de janeiro de 2012 foi editada a Lei de Diretrizes da Política Nacional de Mobilidade Urbana (Lei 12.587/2012), que observou que os Planos Locais de Mobilidade Urbana devem compor a economia do desenvolvimento comportamental, precisando por sua vez está calcado em planejamentos sólidos, que visem melhorar constantemente às condições de mobilidade nos espaços urbanos. Isto evidencia que a baixa qualidade e utilidade dos sistemas de mobilidade urbana, atualmente disponíveis em grandes cidades brasileiras, ainda que elas sejam os principais pontos de investimentos sustentáveis de diversos setores econômicos, devem ser vislumbradas em todas regiões do país, pois levaria condições de acessibilidade e equidade. Este trabalho propõe um conhecimento de pesquisa social em sua metodologia, através da interpretação pelo método documental em pesquisa.
\end{abstract}

Palavras-chave: Políticas públicas; Mobilidade urbana; Cidades; Desenvolvimento urbano sustentável.

\begin{abstract}
High quality transport modes are effective and add dynamism to the economy in smart and sustainable cities, contributing to transformations in the productive economic structure. Therefore, there is a consensus on the impossibility of a society being able to reach high levels of economic development without adopting an efficient transport system, since the evolution of the economy brings with it the need for infrastructure to be expanded, especially the one referred to. to urban mobility. If the Brazilian Traffic Code (National Law 9.503/1997) contains important normative provisions that must be taken into account in the elaboration of urban mobility policy, it is evident that this is a point of sustainable socio economic development. On January 3, 2012, the National Urban Mobility Policy Guidelines Law (Law 12,587/2012) was edited, which noted that Local Urban Mobility Plans must compose the economics of behavioral development, which in turn is based on planning solids, which aim to constantly improve mobility conditions in urban spaces. This shows that the low quality and usefulness of urban mobility systems, currently available in large Brazilian cities, even though they are the main points for sustainable investments in various economic sectors, must be glimpsed in all regions of the country, as it would lead to accessibility conditions. and equity. This work proposes a knowledge of social research, its methodology of social research, through the interpretation by the documentary method in research. Keywords: Public policy; Urban mobility; Cities; Sustainable urban development.
\end{abstract}

\section{Introdução}

Dado o cenário de tendência demográfica de crescimento populacional ascendente, e de alta concentração em grandes metrópoles urbanas, é imposto às cidades desafios complexos nos seus processos urbanísticos subjacentes à mobilidade humana 
e a ação urbana sustentável. Dados os estudos e projeções da ONU, revelam que metade dos 7 bilhões de habitantes do planeta já vivem em metrópoles e garantem que conseguir fazer deslocamentos diários de forma rápida, para a maioria das pessoas em uma maneira eficiente e saudável, ainda é uma realidade distante de ser alcançada em diversos lugares no Brasil. A escolha pública tomada no início do século passado, implementando políticas econômicas de desenvolvimentismo tradicional do Brasil, fazendo com fosse induzido e favorecido ascendente uso individual do automóvel, foi de fato a pior escolha. Os carros ocupam cerca de $90 \%$ das vias públicas e seu uso representa cerca de um terço dos deslocamentos nos grandes centros urbanos, sendo os outros dois terços compostos por viagens a pé e transporte público, a implementação de obras rodoviárias aumentou os intervalos de deslocamento, direcionando a utilização de uma forma de transporte inacessível ainda para a grande parcela população, sendo a resposta eficiente do século XX à necessidade de circulação rápida, paradoxalmente, nos dias atuais acabou levando à paralisia da transição urbana no centro, acidentes, com desperdício de tempo e demais recursos, além dos problemas de poluição ambiental e mudanças climáticas, na ocupação do espaço público por seres humanos. Infelizmente, as desigualdades históricas no Brasil, não apenas de renda, mas também de acesso a bens públicos ${ }^{1}$ e equipamentos sociais urbanos nas cidades acentuaram-se ainda mais nos contrastes urbanísticos nas últimas décadas e por isso ao invés de mitigá-los, dão conformidade às cidades caóticas e disfuncionais com o futuro das demais gerações. Todavia, um conjunto de medidas bem desenhadas aparece, integrado às políticas públicas de mobilidade urbana, apontando sistemas inovativos de mobilidade, garantindo acesso à população e proporcionando melhor bem-estar social e um desenvolvimento urbano e socioeconômico mais sustentável.

$\mathrm{O}$ direito à mobilidade urbana é um dos componentes do direito à cidade. As cidades devem permitir a mobilidade humana de pessoas e a circulação das mercadorias em condições harmoniosas e adequadas. Para tanto, elas devem ser dotadas de um assertivo conjunto de subsistemas de mobilidade. Simultaneamente, a causa e consequência do desenvolvimento econômico e social, da expansão urbana e da distribuição espacial (e localização) das atividades em uma cidade. A estrutura viária e as redes de transportes, portanto, têm especial participação na configuração do desenho demográfico urbano da cidade. Assim diz-se que elas são estruturantes.

Um ecossistema de mobilidade é um complexo, definido infraestrutura urbana, por normas jurídicas, organizações e procedimentos de fiscalização e gerenciamento dessa infraestrutura, por serviços públicos que transportam os passageiros e cargas, por mecanismos institucionais, regulatórios e financeiros de gestão estratégica. A infraestrutura social é composta acessibilidade de calçadas com passeios por pedestres, ciclovias, vias automotivas, metroferrovias, hidrovias, estacionamentos, pontos de embarque e desembarque de passageiros e cargas; terminais, estações, conexões e sinalização de trânsito. As normas jurídicas, as instituições e os procedimentos irão regular o uso dessa infraestrutura urbana e serviços. Esse complexo sistema deve ser estruturado para garantir a toda e qualquer pessoa autonomia nos deslocamentos desejados dentro do espaço urbano, respeitada a legislação em vigor. As políticas públicas de mobilidade urbana estão subordinadas aos princípios de sustentabilidade ambiental e devem estar voltadas à promoção da inclusão social, permitindo o acesso equânime aos bens e oportunidades disponíveis na cidade. Uma boa política pública de mobilidade trata sistematicamente do trânsito, com planejamento e regulação do transporte coletivo, a logística de distribuição das mercadorias, a construção e manutenção da infraestrutura física e social da mobilidade e outros temas afins, como a distribuição espacial das atividades econômicas, culturais, educacionais, de lazer, entre outras.

Desde feito o Código de Trânsito Brasileiro (Lei Nacional 9.503/1997) contém disposições normativas importantes e levadas em consideração na elaboração das políticas públicas de mobilidade sustentável. Em 3 de janeiro de 2012 foi editada a Lei de Diretrizes da Política Nacional de Mobilidade Urbana (Lei 12.587/2012), que deve ser observada pelos Planos Locais de

\footnotetext{
${ }^{1}$ Definição clássica de recursos ambientais - bens públicos.
} 
Mobilidade Urbana ${ }^{2}$ de Mobilidade Urbana que serão elaborados por cada Município e Região Metropolitana, notadamente em consonância dos objetivos, princípios e diretrizes. Enfim, as políticas públicas de mobilidade urbana devem ser tratadas de maneira integrada à gestão urbanística estratégica e participativa, buscando o pleno desenvolvimento das funções sociais das cidades e da propriedade urbana e qualidade de vida das pessoas, de modo sustentável - econômico, social e ambientalmente.

\section{Revisão de Literatura}

Por definição, a mobilidade urbana é um conceito das cidades que têm utilidade de referência às condições das movimentações de seres humanos e bens de produtos no espaço geográfico, a utilização de veículos pelas vias urbanas e estrutura social. Não somente relacionada aos transportes, mas também a demais serviços associados, especialmente à interação da cidade e realização de deslocamentos (Brasil, 2005). Todavia, acontece as possibilidades e capacidades das áreas urbanas com viabilidade que possam ser desenvolvidas pela disponibilização de equipamentos sociais e infraestruturas adequadas de atuações em seus espaços urbanísticos. Assim, a gestão da mobilidade urbana tem requerido estudos e projetos de cidade para serem usada por seus cidadãos, estejam disponíveis os serviços e oferecidas outras coisas também de direito fundamental: emprego, educação, saúde, cultura.

O instrumento legislativo da mobilidade urbana é concebido na Lei de número 12.587/2012 (Brasil, 2012) garantindo as condições de circulação na cidade. A lei que foi aprovada depois de 17 anos em tramitação no Congresso Nacional, é um ponto importante para a gestão das cidades brasileiras, uma vez que possui em sua essência o objetivo de instituir diretrizes da Política Nacional de Mobilidade Urbana - (PNMU) para que sejam aperfeiçoadas as condições de mobilidade dos espaços urbanos (IPEA, 2012). Um dos destaques da PNMU é a obrigatoriedade de que os municípios com mais de 20 mil habitantes desenvolvam planos para a mobilidade urbana, com a finalidade de aperfeiçoar seu desenvolvimento. Os municípios que não desenvolverem seus planos diretor de mobilidade, receberam como punição: bloqueio de recursos do governo federal para investimentos neste setor. Apesar de algumas medidas no setor público que não trazem impactos positivos, a PNMU é considerada um avanço nas ferramentas de planejamento disponíveis, indicando a solução desse problema.

Além disso, a definição de diretrizes é muito importante porque o crescimento acelerado da densidade demográfica das cidades, atrelados pela ausência de planejamento sobre as questões de mobilidade urbana, vem contribuindo para dificultar a melhoria da qualidade de vida urbana e tem levado ao aumento dos gastos das pessoas com transporte (Duarte et al., 2007). De modo geral, "a necessidade de movimento dos cidadãos depende de como a cidade está organizada territorialmente e vinculada funcionalmente com as atividades que se desenvolvem no espaço urbano” (Duarte et al., 2007, p. 12). Tal que seja importante um conjunto de diferentes políticas públicas relacionadas para conseguir enfrentar esse problema público do mundo contemporâneo, os efeitos são diversos e benéficos nas diferentes faixas de renda da sociedade. Mas, entretanto, são a maioria dos mais pobres afetados pela falta de acesso a bens públicos e também por terem suas residências afastadas dos locais centrais da cidade onde a movimentação e o acesso aos equipamentos sociais e serviços públicos são muito restritos. Na qual um dos seus principais desafios a efetividade das políticas públicas de mobilidade urbana é promover o desenvolvimento através da facilitação do acesso de grande parte da população ao direito à cidade. Uma variável que contribui para dificultar as condições dos deslocamentos das pessoas e bens nas cidades é o crescente uso do transporte individual motorizado, que tem causado efeitos

\footnotetext{
${ }^{2}$ Em outras palavras: a política de mobilidade deve estar associada à política de desenvolvimento urbano, submetendo-se às diretrizes expressas nos Planos Diretores Participativos. O Estatuto das Cidades (Lei Nacional 10.257/2001) estabeleceu em seu artigo 41, $§ 2^{\circ}$, a obrigatoriedade das cidades com mais de 500 mil habitantes elaborarem seus Planos de Transporte Urbano Integrado, compatível com o seu Plano Diretor, ou nele inserido. Porém, considerando que o planejamento estratégico é condicionante de uma gestão pública eficiente, é recomendável que todos os Municípios elaborem de maneira democráticaparticipativa seus Planos de Mobilidade Urbana.
} 
bastante negativos nas cidades pelo desperdício de tempo ao deslocamento de casa para os locais de trabalho, poluição atmosférica, perdas econômicas e financeiras, diminuição do bem-estar das pessoas.

Segundo Scarlato (2003, p. 374), as escolhas públicas no Brasil, ao transporte individual automotivo, resultado da conveniência dos diferentes governos que se sucedem até a atualidade, comprometeram uma política boa e séria para o desenvolvimento e economia de transportes, mesmo âmbito elas destruíram a política de urbanização, criando dificuldades para os projetos de renovação urbana das cidades brasileiras. Na qual o grande aumento do número de automóveis e motocicletas está em escolhas equivocadas de políticas econômicas que desarranjam setores com vários incentivos mal desenhados para a indústria automobilística.

A Mobilidade Urbana Sustentável considera que o resultado da interação de vários agentes na dinâmica dos processos urbanos das cidades, portanto devemos considerar todas as partes de sua dimensão, que estão interligadas de forma entrelaçada, onde há uma interação social que se retroalimenta, em uma abordagem da economia da complexidade para melhor compreensão desse fenômeno. Na prática é concebido como exemplo: quando o trânsito retroage sobre o transporte que é afetado por ele (Terán, 2013). Todavia, a mobilidade sustentável está em um sistema com seus três subsistemas:

* Transporte;

* Trânsito;

* Uso do solo.

A seguir, a Figura 1 representa a conexão dos três subsistemas da mobilidade sustentável:

Figura 1: A conexão dos três subsistemas da mobilidade sustentável.

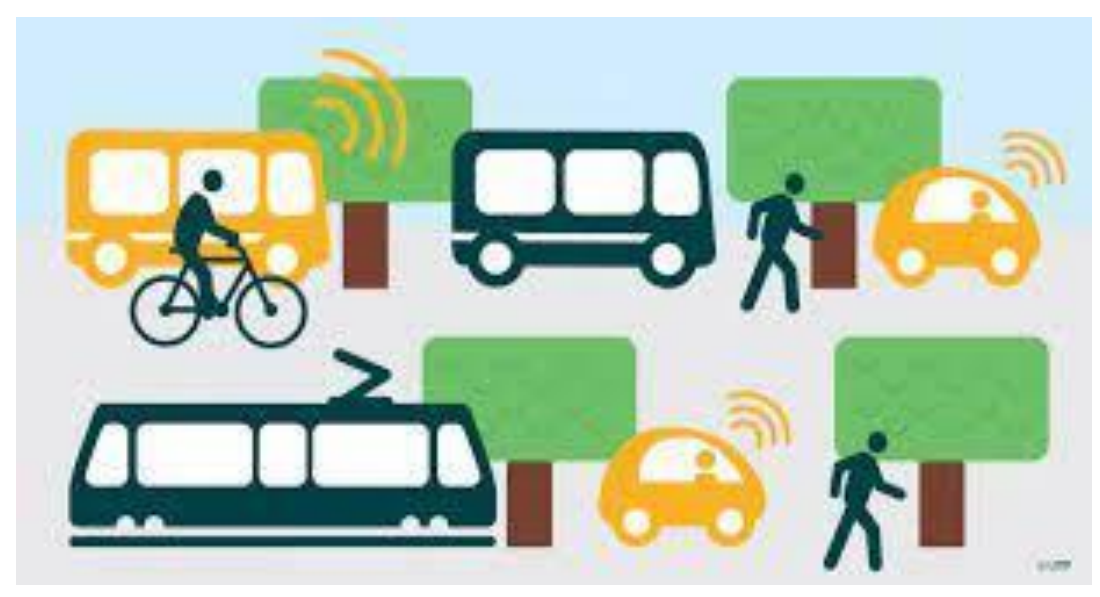

Fonte: wilbrasil.org.br (2021).

O ecossistema de mobilidade é considerado sustentável quando a curva de possibilidades individuais e coletivas de escolhas para os seus deslocamentos urbanos, a potencialidade de escolhas dos cidadãos na utilidade dos serviços, de tal forma com que a cidade realmente seja acessível a todas as pessoas sem discriminação (Sanz Alduán, 1997). Dessa forma quanto mais acessível um sistema de mobilidade sustentável mais facilidades nos deslocamentos e geração de valor aos lugares, como serviços de saúde e de educação, cultura e lazer, empregabilidade, novos negócios sustentáveis, aumento dos benefícios ele trará para o indivíduo e o conjunto da sociedade. A capacidade de redução das da pobreza e inclusão social está efetivamente interligado ao conceito de sustentabilidade, adotado a mobilidade urbana, o conceito abrangente e agrega também os impactos dos modos de transportes urbanos no meio ambiente. por isso é importante a gestão dos transportes está no centro do debate para uma transição energética no mundo, com preocupações legítimas e integradas ao atendimento das satisfações das pessoas no presente, com 
responsabilidade e preservando a capacidade das próximas gerações no futuro. Notadamente, a presença sustentável do setor de mobilidade urbana em uma cidade é necessário verificar as medidas técnicas de economia circular sobre os resíduos sólidos e também os tóxicos lançados cotidianamente pelos transportes que lançam poluição ambiental. As pessoas que residem na periferia da cidade enfrentam maiores dificuldades de acesso nos meios de locomoção, apresentando ótimas condições de conservação e em qualidade; se os preços das tarifas são refletidos no serviço entregue, justos serão aplicados incentivos e subsidiados aos cidadãos (SUMMA, 2005).

Entretanto, é necessário um olhar multidisciplinar ao analisar a mobilidade e pensar como o setor está diretamente interligado com seus efeitos de causa nas cidades, no trânsito, transporte, elaboração do uso do solo através do zoneamento ecológico-financeiro de áreas industrial, comercial entre outros. A utilidade específica de determinada região da cidade faz com o seu solo, como está relacionada em função da utilização do solo, onde tudo dependerá das suas escolhas de uso (Terán, 2013). Acontece também com o trânsito como são definidos o modo de transporte,pois ocorre variações de ofertas disponíveis em tal região da cidade. A ausência de uma linha de transporte, pode ser uma variável importante na desutilidade de determinadas funções para o uso do solo em certas localidades, tanto para moradia, comércio e demais atividades econômicas. A existência ou não dessa rede irá definir a formação do fluxo de trânsito que será notado pelas pessoas (Terán, 2013). Na linha a seguir, a Figura 2 apresenta o fluxo de esquema pelas pessoas:

Figura 2: O fluxo de esquema pelas pessoas.

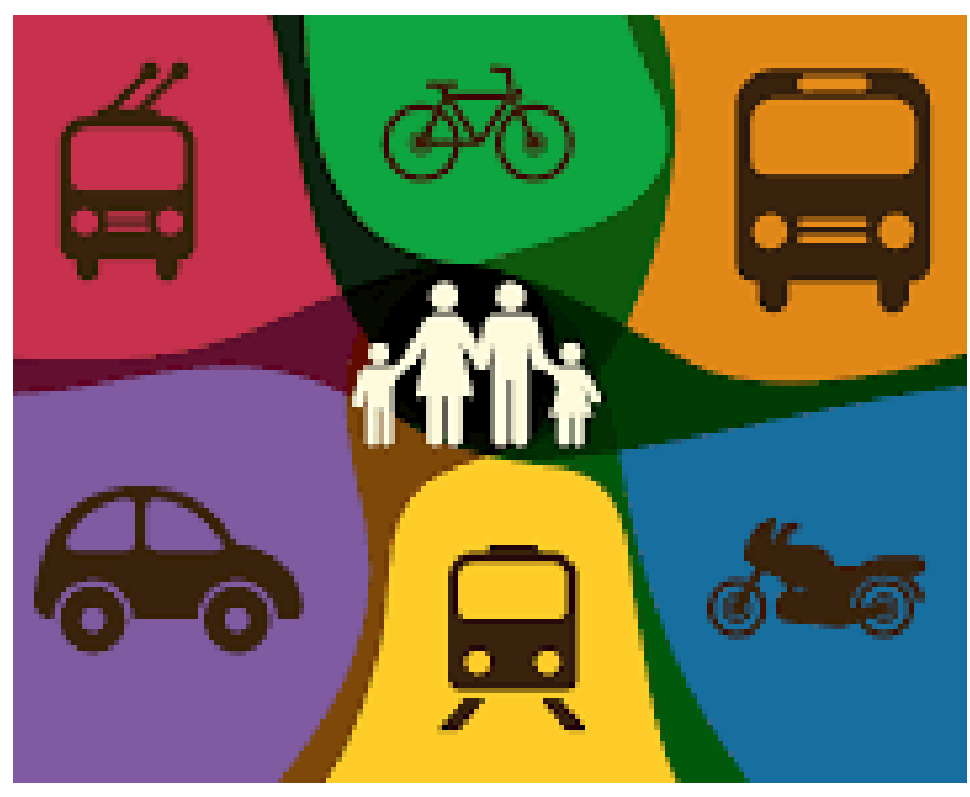

Fonte: wilbrasil.org,br (2021).

O esquema representado pelas pessoas, deixa claro que uma abordagem de mobilidade urbana, não é restrito a algo específico, porque seus fundamentos são complementares, a produção de conhecimento deve ser suficiente para a compreensão da realidade, notadamente é que há uma vinculação que evidencia o conjunto como o todo e que se estabelece e uma lógica de um circuito que é necessário contextualizar. (Terán, 2013). Essa teoria é de grande utilidade, para os formuladores de políticas públicas e projetistas da mobilidade urbana, onde qualquer um dos problemas a serem solucionados, as três variáveis devem ser analisadas.

A partir da análise do contexto, colocando em prática a mobilidade urbana sustentável considerada como seu objetivo de estudo que deve ser feita a promoção pela redução dos impactos dos custos ambientais e socioeconômicos dos transportes, 
pela busca de viés ambiental eficaz na locomoção feita pelas pessoas. Devendo ser adotada uma estratégia de substituição dos modos de transporte que causam mais impactos negativos. (Sanz Alduán, 1997). As funções de minimização de custos logísticos dos veículos motorizados, a construção de infraestrutura física e social de equipamentos públicos, permitindo o rápido acesso até eles a pé e de bicicleta. Uma gestão e restauração de áreas degradadas do tecido social urbano socioambiental, para que o solo tenha sua função de uso, na criação de novas funções urbanas em locais estratégicos à mobilidade (geração de empregos e de opções de lazer em áreas periféricas da cidade, por exemplo). O controle do uso do solo para evitar que em determinadas regiões do espaço urbano sejam desenvolvidas uma única função, referência à mobilidade urbana sustentável. A sustentabilidade das cidades inteligentes através da mobilidade humana pode ser definida pela sua capacidade de permitir o acesso democrático das pessoas ao espaço urbano. Através desse conceito é possível criticar e propor melhorias aos modelos de planejamento adotados na gestão urbana. Essa análise é com base no estudo de Terán (2013), que defende que o acesso aos benefícios que a cidade oferece para as pessoas dependerá essencialmente da integração das atividades no espaço urbano. Quando a mobilidade sustentável é debatida, surge a importância de uma visão sistêmica se tornar evidente, pois há uma forte demanda para se entender as relações de causa e efeito entre o sistema de transporte e a formulação de políticas públicas. Todavia, a sustentabilidade no sistema de transporte não requer apenas medidas técnicas, que não serão suficientes se não vierem acompanhadas de mudanças no comportamento das pessoas em seus deslocamentos (SUMMA, 2005).

Diferentes medidas para o atingimento das metas de um sistema de transporte sustentável que permitam o desenvolvimento científico e tecnológico de energias renováveis (SUMMA, 2005). Existem evidências de que tratar a temática da mobilidade urbana e economia dos transportes de modo isolados é também uma das causas que geram deficiências nos processos decisórios de políticas públicas do setor para o atendimento dos objetivos devem ser dotadas de medidas em diversas partes para encontrar soluções para os problemas complexos dos sistemas de mobilidade urbana sustentável de transportes pela ligação com outros setores (SUMMA, 2005)

\section{Metodologia}

A pesquisa social é uma atividade que é realizada para encontrar uma resposta ou explicação sobre um determinado fenômeno social. Uma pesquisa social propõe um conhecimento de pesquisa social. Para isso, o método documental também é às vezes chamado de método interpretativo retrospectivo prospectivo. Nesse caso, a pesquisa social, passa a ser documental. O método documental, todavia, é um termo específico da etnometodologia. Apesar do nome, não é um processo que faz uso de documentos escritos nem é um método específico de trabalho (como uma pesquisa). O método documental não deve ser confundido com a análise de documentos em outros campos, como linguística, histórica ou crítica literária. Também não deve ser confundido com técnicas como análise de conteúdo ou semiótica. Não é o mesmo que "métodos documentais", referentes ao exame minucioso de documentos destinados a revelar as circunstâncias sociais em que os documentos são produzidos. Este trabalho busca definir a importância das políticas públicas de mobilidade urbana e sustentabilidade inteligentes para as cidades, a pesquisa bibliográfica pela revisão de literatura, tem natureza de análise exploratória (Gil, 2002) e propõe diversas medidas descritivas sobre o tema.

\section{Resultados e Discussão}

\section{Sustentabilidade Social}

Os impactos no âmbito social do setor de mobilidade urbana sustentável, parte do entendimento da economia do bemestar no espaço urbano, no que a cidade deveria proporcionar em bens públicos para as pessoas, levando a melhores condições de vida para o conjunto da sociedade. Porque é experimentado quando a mobilidade é levada em sua dimensão urbana, assume 
características específicas, em termos de qualidade de vida das pessoas que vivem no espaço urbano, dependem em grande medida da estrutura disponibilizada para os deslocamentos no seu cotidiano (Ribeiro \& Ribeiro). Até mesmo os indivíduos que farão seus deslocamentos individualmente, em veículos próprios, seriam beneficiados, porque usufruíram dos equipamentos públicos urbanos de infraestrutura física disponibilizados para o coletivo, a movimentação depende de melhor infraestrutura urbana e de condições de mobilidade, disponíveis na geografia econômica da cidade. Contribuindo para integrar diferentes níveis urbanos conectando o bem-estar entre diversas pessoas (Ribeiro \& Ribeiro, 2013).

Especialmente em razão para a existência de sistemas de transporte é que sua utilidade na provisão de serviços pelo fato de ser um grande facilitador para que pessoas realizem suas funções sociais básicas. Desse modo, há um grande número de impactos positivos que podem ser vislumbrados: mobilidade de trabalhadores, capitais, fluxos de informações, desenvolvimento socioeconômico e tecnológico, entre outros. Porém, esses benefícios não são sentidos da mesma forma por todas as pessoas, uma vez que as pessoas marginalizadas e outras carentes de recursos financeiros são impossibilitadas de acesso aos serviços e equipamentos públicos (SUMMA, 2005). Em razão dos altos preços cobrados - que não podem ser sustentados por faixas mais inferiores de renda, da distribuição desigual dos modos de transporte no território da cidade, levando a grupos de pessoas a serem excluídos da sociedade, como um entrave ao desenvolvimento socioeconômico e aumento do bem-estar urbano (SUMMA, 2005). De acordo com de Ribeiro e Ribeiro (2013, p. 234) as formas precárias e insuficientes de deslocamento asseguradas por um sistema de mobilidade ineficiente gera efeitos contrários aos ganhos de renda obtidos pelos trabalhadores na atual conjuntura macroeconômica e desigualdades. A concentração da oferta de trabalho nas áreas centrais dos grandes centros urbanos e o crescimento da população vivendo em periferias distantes têm sido os principais pontos de impacto em termos de deslocamento para acesso a emprego e renda. Na qual é aprofundado pela precariedade e por deixar de lado o sistema público de transportes, elevando a média de tempo que é gasto cotidianamente por seus moradores na locomoção, com reflexos diretos estado de bemestar urbano (Ribeiro \& Ribeiro, 2013). No entanto, caso tenha uma crise no sistema de mobilidade urbana impacta de forma desigual as diferentes camadas de renda de acordo com suas condições sociais, desde de moradia, até o aumento da média de tempo desperdiçada no meio do trânsito. Gestão do tempo que poderia ser produtiva e melhor alocada na realização de outras atividades como lazer pessoal, ao convívio com a família, à educação, entre tantas outras. Deste modo o meio de transporte público é um serviço essencial, um direito básico universal para que as pessoas possam se locomover com liberdade para realizar suas atividades, o que deixa explicito a necessidade de atenção por parte dos tomadores de decisão no setor público para que criem condições do espaço urbano seja facilmente acessado por todos. A equidade de acesso e um transporte adequado são fundamentais para a inclusão social e para se avançar em direção à sustentabilidade? (Machado, 2010, p. 66). Ainda destacando que o preço da tarifa é pouco subsidiado e tem mais impactos na população de baixa renda, levando a segregação espacial. As políticas públicas de mobilidade urbana podem ser direcionadas como "motores de crescimento e desenvolvimento econômico", para uma estratégia efetiva de inclusão social, potencializada pelo acesso dos cidadãos aos serviços oferecidos. Mas as regiões metropolitanas é que as condições precárias de mobilidade urbana, sobretudo no que diz respeito à disponibilização do transporte público, tem ido na contramão da inclusão social, gerando uma maior exclusão social. (Machado, 2010).

Alguns indicadores de mobilidade podem ser analisados para quantificar os impactos sociais do sistema de transporte, assim é possível medir os impactos da exclusão e da inclusão social. Usando como base para formular políticas públicas de acesso aos serviços básicos para a população que não possui veículos automotores, as condições de acessibilidade das pessoas com deficiência e o orçamento familiar tem capacidade de pagamento das tarifas para os grupos de baixa renda, no geral, os gastos com transporte não devem exceder 20\% do orçamento das famílias (Machado, 2010). Fontgalland e Oliveira (2021) apresentam o caso de Campina Grande referindo-se aos novos espaços contingentes de mobilidade urbana. 
Segundo Pereira e Schwanen (2013), o tempo gasto pelas pessoas em seus deslocamentos deve ser interesse central para as políticas públicas de mobilidade urbana, porque os níveis de congestionamento geram muitos impactos negativos na qualidade de vida das pessoas. Assim, a Região Metropolitana do Rio de Janeiro (RMRJ) tem a pior avaliação do Brasil, com o tempo médio de deslocamento de casa ao trabalho calculado em 50 minutos (FGV, 2014). O de impacto destacado não é apenas na Região Metropolitana do Rio de Janeiro, mas infelizmente, na maioria das cidades de porte médio e grande das nossas cidades, sendo o resultado do um modelo adotado transportes insustentável em sua essência, pois sua orientação é transporte individual motorizado, em contraposição ao modelo mais viável de diversificação do modais de transportes e mobilidade sustentável. Construir uma infraestrutura urbana e social para a mobilidade dos sistemas de transporte também tem impactos socioeconômicos, porque ao romper as estruturas existentes, melhorar a distribuição de renda, reduz o risco de acidentes no trânsito, aumenta a qualidade de vida e saúde humana. Criando espaços para a caminhabilidade e para atividades culturais com bicicletas (SUMMA, 2005).

\section{Sustentabilidade Ambiental}

Para o funcionamento dos sistemas de transportes, existe uma alta demanda de recursos ambientais, recursos naturais limitados que não são renováveis em grande medida. A energia dos transportes é responsável por movimentar o setor, segundo projeções estimadas: um quarto de toda a energia usada no planeta terra. Os combustíveis fósseis têm metade da demanda mundial de petróleo proveniente do setor de transportes (SUMMA, 2005). Um outro recurso bastante utilizado também é a terra, não apenas requisitado para a construção do sistema viário, mas também para estacionamentos, manutenção de veículos e instalações de fábricas. A terra, um recurso ambiental que deveria ser usada para uma agricultura sustentável em espaços urbanos nas cidades, em construção de áreas verdes e preservação do meio ambiente, são usadas nas vias para veículos motorizados que aumenta a demanda por transportes, já nossos alimentos diários são produzidos e transportados em longas distâncias até o comércio, que também ficam mais caros pelo custo da logística. Os cidadãos precisam de grandes deslocamentos para apreciar áreas verdes, a natureza e de ter contato com o meio ambiente. Esses fatores contribuem para o fenômeno conhecido como espraiamento urbano (SUMMA, 2005).

O atual modelo tradicional de planejamento urbano das metrópoles, onde sua paisagem automobilística é constituída pelo fenômeno espraiamento urbano, formado nos Estados Unidos e predominante em todo o mundo. Entretanto, mesmo que os veículos fiquem mais sustentáveis, com o desenvolvimento científico de novas tecnologias ambientais, é necessário que as distâncias e locomoção sobretudo por transporte individual motorizado, já que rede de transportes públicos porque não têm a capacidade de atendimento não é igualitária em diversas partes de uma cidade, acabam sendo inviáveis do ponto de vista financeiro devido à baixa densidade de algumas regiões (Barczak \& Duarte, 2012).

Os deslocamentos na mobilidade urbana das médias e grandes cidades é baseada em grande parte pelo intenso uso do automóvel individual e que tem elevados custos ambientais. Os argumentos da classe política estão cada dia mais sendo alinhados com questões ambientais. Todavia, o que se observa nas decisões majoritárias que são tomadas em países não têm enfatizado medidas que reduzam os efeitos negativos do sistema de transporte, contribuindo para redução as emissões de gases do efeito estufa (GEE). (Barczak \& Duarte, 2012).

No Brasil, em especial as decisões políticas do governo federal, como também em outras esferas públicas como em nível estadual e municipal, ligadas à mobilidade urbana e meios de transportes, têm causado enormes prejuízos ambientais, pois priorizam o transporte por automóveis e motocicletas. Essa má condução da política fiscal vale destacar: a redução do Imposto sobre Produtos Industrializados (IPI) para aquisição de veículos, baixo preço cobrado pelo Imposto sobre Propriedade de 
Veículos Automotores (IPVA), incentivo à produção de motocicletas na Zona Franca de Manaus; grandes incentivos fiscais para instalação de fábricas de automóveis (Silva, 2011).

\section{Sustentabilidade Financeira}

O terceiro pilar da sustentabilidade que são relacionados aos aspectos econômico-financeiro do setor de mobilidade urbana, podemos definir como uma atividade econômica e cultural que por meio dela dar apoio ao sistema econômico na produção de bens e serviços, que é uma variável fundamental para qualquer sistema produtivo de um país e que seu potencial seja utilizado de forma ótima e plena na alocação dos recursos disponíveis. Os pressupostos do desenvolvimento econômico e social, a ocupação territorial, economia da energia e do meio ambiente. Desse modo, os processos econômicos estão entrelaçados a mobilidade urbana, as políticas públicas e os instrumentos de planejamento setorial são muito requisitados para as estratégias globais de expansão de uma economia (Barat, 2007). Todavia, porque em toda a literatura econômica os transportes têm grande participação com os processos de desenvolvimento socioeconômico, analisando a economia como um todo. Na sua forma que é disponibilizada tem impactos nas modificações de estoques e medidas de combinações dos fatores de produção, como também com as transformações e inovações na estrutura das demandas intermediárias e finais (Barat, 2007). É por causa disso, que tem ganhando espaço as evidências científicas sobre o tema sobre atenção dos pensam, tomam decisões no setor público e em executivos de empresas sobre os impactos dos congestionamentos na economia e desenvolvimento regional, na forma que os fatores marginais são adicionados mais custos aos produtos em decorrência das dificuldades logísticas e dos atrasos comerciais das entregas (Resende \& Souza, 2009). Porque é o congestionamento uma das variáveis observadas por empresários quando planejam iniciar abertura de projetos e em novos negócios nas localizações ainda não atendidas, exercendo negativa influência nesse processo decisório, fazendo buscar alternativas menos arriscadas, evitando prejuízos financeiros ao problema. (Resende \& Souza, 2009). Os problemas relacionados à mobilidade logística das mercadorias nos grandes centros urbanos, impactam os ganhos de produtividade da uma economia em suas atividades realizadas. É importante que os sistemas de mobilidade e transportes possam contribuir para o desenvolvimento, para isso tem a possibilidade de circulação de finanças e mercadorias nas geografias urbanas e econômicas da cidade com eficiência e devida segurança.

Os modais de transportes diversos de alta qualidade são eficientes e eficazes, agregando dinamismo na economia em cidades inteligentes e sustentáveis, contribuindo para distribuição de renda e produtividade nas transformações na estrutura econômica e inovações tecnológicas verdes. Portanto, existe consenso sobre a impossibilidade de que uma sociedade consiga atingir grandes níveis de desenvolvimento econômico sem adoção de um sistema de transporte eficiente, uma vez que a evolução da economia é necessária para que sua a infraestrutura seja desenvolvida, em especial a referente à mobilidade urbana sustentável. (Barat, 2007). Se um dos atrativos aos investimentos produtivos em uma determinada região, quanto a cidade tem a capacidade de oferta de uma estrutura para atuação dos mercados, dinamizando sua economia local e demandando capital humano através de oportunidades de trabalho, deve direcionar suas políticas públicas voltadas a mobilidade urbana, com planejamento estratégico, apoio técnico em financiamentos de projetos de infraestrutura e sustentabilidade pelos bancos de desenvolvimento e instituições financeiras e possibilitando o destravamento de investimentos sustentáveis, contribuindo para mudança de comportamento urbano, fomento a setores econômicos e culturais, melhorando a distribuição de renda básica, cidadania, qualidade de vida das pessoas e o desenvolvimento urbano sustentável como liberdade.

\section{Conclusão}

A mobilidade urbana se insere em três objetivos: gerar alternativas viáveis para enfrentar o problema de mobilidade urbana; estabelecer parâmetros; e projetar os resultados que essas alternativas possam atingir métricas de tempo/percurso. Como 
as Políticas Públicas de Mobilidade Urbana são relativamente recentes, sem um contexto de análise de cenários, onde é requerida desde sua fase de formação, implementação de medidas e estendendo até a última etapa do ciclo da política pública, compreendemos também que a abordagem da complexidade, onde vários atores econômicos interagem cotidianamente, levando as demandas em busca de soluções que atendam com impactos positivos desse conjuntos de medidas de políticas públicas de mobilidade urbana na arquitetura das escolhas. Considerando o status quo na PNMU, identificamos que o maior problema é a falta de subsídio às tarifas de transporte público aos consumidores, desenhos de incentivos para o uso mais sustentável para deslocamentos nas cidades, a falta de qualidade do gasto público em projetos de infraestrutura urbana e economia dos transportes, sendo importante mais transparência na aplicação dos recursos da sociedade e evidências científicas na formulação de políticas públicas.

Partindo do ponto da caminhabilidade, Fontgalland e Oliveira (2021) oportunizam a discussão dos desafios da gestão pública e apontam como quão complexa é a temática da mobilidade urbana. A bicicleta é um instrumento de locomoção que foi requerido desde o início da política pública, para diversificar os modais de transporte, pela experiência do mundo nas cidades globais é o mais viável, trazendo ganhos de produtividade na economia e cadeias de valor. Utilizando o conceito da economia comportamental na sua técnica de Nudge onde as escolhas mudam os comportamentos das pessoas através de soluções baratas, tendo em vista o grande aumento de automóveis que circulam e o caos planejado do trânsito que muitas vezes impedem uma melhor circulação e gera desperdícios de tempo, a bicicleta assegura como um meio de locomoção que além de facilitar a ida e vinda devido a sua estrutura, trás diversos benefícios tanto ambientais, como financeiros, também melhora a qualidade de vida de usa com frequência. As ciclovias induzem as pessoas a utilizarem a bicicleta, por se sentirem mais seguras ao terem seu espaço de locomoção adequado, fazendo as pessoas frequentarem os espaços públicos mais facilmente.

Os desafios de implantação e execução dos sistemas de mobilidade, mas sua avaliação e monitoramento por meio de indicadores (smart cities), das metas e universalização de uma melhor oferta de transporte público de qualidade, precisam de planejamento e instrumentos que consolidam a gestão democrática das cidades na garantia da construção contínua do aprimoramento da mobilidade urbana, com um importante potencial de conectar pessoas e atividades. Entretanto, apesar do avanço que representa a recente Lei da Mobilidade Urbana, as cidades brasileiras ainda engatinham na transformação e na utilização de seus espaços públicos, quando analisamos a distribuição espacial da infraestrutura para o seu uso em algumas cidades, fica evidente a necessidade de priorização de políticas públicas voltadas à mobilidade e utilidade da bicicleta, que garantam a segurança nos deslocamentos urbanos e protejam a vida dos ciclistas e pedestres, a implementação dessas políticas combinadas, ampliação da rede cicloviária e instalação de bicicletários públicos, pode significar custos e tempos significativamente mais baixos nos deslocamentos. As medidas também podem promover benefícios socialmente justos e sustentáveis. para atender as demandas democráticas da sociedade.

Recomendamos ainda que as questões propostas neste artigo possam ser aprofundadas e devem ser exploradas pela comunidade acadêmica e científica para a sociedade, em trabalhos futuros nesta linha de pesquisa que é relativamente nova e carente de conhecimento acessível com conceitos e tipologias da temática tanto do aspecto qualitativo, como quantitativo em índices e sistemas de aplicações a mobilidade sustentável e inteligente, onde pesquisadores e policy makers podem ter o apoio de evidências na tomada de decisão no âmbito do planejamento das cidades para um modelo de desenvolvimento urbano mais humano e sustentável.

\section{Referências}

Barat, J. (2007) Logística, Transporte e Desenvolvimento Econômico: a visão econômica. Editora CLA.

Barczak, R. \& Duarte, F. (2012) Impactos ambientais da mobilidade urbana: cinco categorias de medidas mitigadoras. Revista Brasileira de Gestão Urbana. 
Blue, E. (2016). Bikenomics. Como a bicicleta pode salvar a economia. Babilônia.

Bolle. M. B. D. (2020). Ruptura. Intrínseca.

Brasil. Constituição (1988). Constituição da República Federativa do Brasil: promulgada em 5 de outubro de 1988. Contém as emendas constitucionais posteriores. Senado.

Brasil. (1997). Lei no 12.760, de 20 de dezembro de 2012. Altera a Lei n. 9.503, de 23 de setembro de 1997, que institui o Código de Trânsito Brasileiro.

Brasil. (2005). Ministério das Cidades. Mobilidade urbana é desenvolvimento urbano.

Brasil. (2013). Ministério do Planejamento. MPOG.

Brasil. (2021). Ministério do Desenvolvimento Regional. Pesquisa Nacional de Mobilidade Urbana 2021.

Bresser-Pereira, L.C. (2006) O conceito histórico de desenvolvimento econômico. FGV.

Carvalho, L. (2018). Valsa brasileira: Do boom ao caos econômico. Todavia.

Carvalho, L. (2020). Curto-circuito: O vírus e a volta do Estado. Todavia.

Comissão Europeia. Cidades para Bicicletas, Cidades de Futuro. (2000) Luxemburgo.

Estatuto da Cidade. Lei n. 10257 de 2001. (2001) Constituição Federal 1988.

Felix, A.C. Fontgalland, I. L. Limeira Filho, A. Pereira, A. P. Martins, M. F. (2021) Mobilidade urbana no contexto do município de Campina Grande/PB: uma abordagem à luz do paradigma das cidades sustentáveis. Revista Ibero-americana de Ciências Ambientais.

Fernandes, G.S. (2015) Impactos da Mobilidade Urbana na Região Metropolitana do Rio de Janeiro. Monografia (Curso de Administração Pública) Universidade Federal Fluminense - UFF.

Fioravanti, C. \& Saldiva, P. (2016) Por uma cidade mais saudável. Revista Pesquisa Fapesp.

FGV (Fundação Getúlio Vargas). Série Estados Brasileiros. (2014).

Fontgalland, I. L. \& Oliveira, C. (2021) The duality of urban mobility as a heterogeneous phenomenon in the construction of sustainable living space in cities: a look at the inference of poverty in the city of Campina Grande, Brazil. International Journal of Development Research..

Gil, A. C. (2002). Como elaborar projetos de pesquisa (4. ed.). Atlas.

IBGE (Instituto Brasileiro de Geografia e Estatística). Pesquisa Nacional por Amostra de Domicílios - PNAD 2012. (2012) IBGE.

IPEA (Instituto de Pesquisa Econômica Aplicada). Mobilidade urbana no Brasil. (2010)

IPEA (Instituto de Pesquisa Econômica Aplicada). A Nova Lei de Diretrizes da Política Nacional de Mobilidade Urbana. (2012)

IPEA (Instituto de Pesquisa Econômica Aplicada). Indicadores de mobilidade urbana da PNAD em 2012. (2013)

IPEA (Instituto de Pesquisa Econômica Aplicada). Modelagem de sistemas complexos para políticas públicas. (2015)

LABMOB (Laboratório de Mobilidade Sustentável) Economia da Bicicleta no Brasil. (2018) Universidade Federal do Rio de Janeiro.

Machado, L. (2010) Índice de mobilidade urbana sustentável para avaliar a qualidade de vida urbana. Dissertação (Mestrado em Planejamento Urbano e Regional) Universidade Federal do Rio Grande do Sul

MOBILIZE Brasil. Quem Somos. (2021)

MPPR (Ministério Público do Estado do Paraná). Habitação e Urbanismo. (2021) MPPR.

Oliveira, C. G. \& Fontgalland, I. L. (2021). Análise da mobilidade urbana, em cidades de porte médio por meio da sintaxe espacial. Curitiba: Appris.

ONU (Organização das Nações Unidas). (2019). Perspectivas Mundiais de População: Estudo da Divisão de População do Departamento da ONU de Assuntos Econômicos e Sociais.

Pereira, R. H. M. \& Schwanen, T. (2013) Tempo de deslocamento casa-trabalho no Brasil (1992-2009): diferenças entre regiões metropolitanas, níveis de renda e sexo. Livraria do IPEA.

Pindyck, R. \& Rubinfeld, D. (2013) Microeconomia. Pearson Education do Brasil.

PNMU (Política Nacional de Mobilidade Urbana). Lei 12.587/12. (2012).

Resende, P. T. V. D. \& Sousa, P. R. D. (2013) Mobilidade urbana nas grandes cidades brasileiras: um estudo sobre os impactos do congestionamento. Brasil. 
Ribeiro, L.C.Q. \& Ribeiro, M.G. (2013) (Org.). IBEU: Índice de Bem-Estar Urbano. Letra Capital.

Scarlato, F. C. (2003) O espaço industrial brasileiro. Geografia do Brasil. Edusp.

Sanz Alduán, A. (2007) Movilidad y accesibilidad: un escollo para la sostenibilidad urbana. In: Boletín. Madrid: Instituto Juan de Herrera.

Secchi, L. (2012). Políticas Públicas: conceitos, esquemas de análise, casos práticos. Cengage Learning.

Sen, A. (2010). Desenvolvimento como Liberdade. Companhia de Bolso.

Silva, E. F. (2014) Meio Ambiente e Mobilidade Urbana. Editora Senac.

Silva, E. R. D. (2011) Análise do Crescimento da Motorização no Brasil e seus Impactos na Mobilidade Urbana. Dissertação (Mestrado em Engenharia de Transportes) Universidade Federal do Rio de Janeiro. Rio de Janeiro.

SUMMA (Sustainable Mobility, Policy Measures and Assessment). (2005). Rand Europe.

Terán, J. A. (2013) Mobilidade Urbana Sustentável. Scortecci.

Thaler, R. H. (2019) Nudge: Como tomar melhores decisões sobre saúde, dinheiro e felicidade. Editora Objetiva.

Vasconcellos, E. A. D. (2012) Mobilidade Urbana e Cidadania. SENAC.

Vasconcellos, E. A. D. (2013) Mobilidade Urbana - O que você precisa saber. Companhia das Letras. 